He has left a family of two sons and one daughter, his elder son being the energetio and successful Superintendent of the Sussex County Asylum.

In the office of Honorary Secretary of this Association, held from 1847 to 1855, the late Dr. Williams succeeded Dr. Hitch (his predecessor also at the Gloucester County Asylum), who was the first secretary and the earliest promoter of the Society, and who still survires, at a very advanced age.

\title{
M. BrocA.
}

When in a recent number we ohronioled M. Broca's elevation to the Benate, we little thought that in 80 brief a spece of time we should have to lament his death, at the comparatively early age of 56 . The lose to seience, more or less nearly allied to our own department, is simply irreparable. He was, by his brilliant researahes into the funotion of the convolution which bears his name, directly associated with medical psychology.

" He wes born in 1824, at Sainte-Foy (Aironde), the birthplace also of Gratiolet, and was the son of a physician." In 1866 he became a member of the $\Delta$ cademy of Medicine, and in 1867 was promoted to a chair at the Faculty as a teacher of clinical surgery.

"The natural bent of Broca's mind received an additional impulse by the foundation (in 1860) of the Anthropological Society, in which he met his old friend Gratiolet. From that moment the activity of Broca's intellect seemed to have found its proper channel. Anthropology is a compound of so many other sciences - in which anatomy, natural history, ethnology, archs: ology and philology take an equal part-that the intervention of a grasping and encyclopmdic mind like Broca's is almost invaluable to form the connecting link between so many different branches of human knowledge which, at first sight, would seem to lie widely apart. An excellent mathematician, a first.rate anatomist, a good Greek scholar, Broos combined in himself that diversified knowledge which the subjeot requires, with the synthetical tendencien which condense these disseminated forces and make them converge upon a single point.

"On Tueeday, the 6th inst. (July) he fainted in the Senate House; on the ensuing Wednesday he felt sufficiently recovered to resume his labours but towards midnight on Thursday he was suddenly seized with a fit of dyspnces, rose from his bed, and expired in ton minutes. Strange to say, the post-mortem examination gave no clue to the mystery of his unexpected death, all the organs being apparently sound. We shall probably not be far from the truth in attributing the catastrophe to cerebral exhaustion, arising from too protracted a course of severe intellectual exertion.

"At the banquet which his friends offered him on the occasion of his election to the Benatorial dignity, Broca observed, in returning thanks, that if he believed in ancient superstitions he ought to expect some great misfortune, as the penalty for too complete and long-continued prosperity. That misfortune came in the form of sudden death; but in the very bitterness of their grief his friends can scarcely regret that he should have been spared the protracted sufferings of ohronio disease, and that he should have disappeared from sight in the fulness of his glory."

The British Modical Journal, after saying that M. Broca was below the ordinary stature, but had a remarkably large head, states that at the autopsy tbe brain was not found to be so large as anticipated, but the frontal lobes were greatly developed. The brain and its membranes weighed nearly 500zs. aroirdupois. The writer refers his death to angina pectoris.

He was buried in the cemetery of Mont Parnasse, the funeral service being performed by a Protestant pastor, and eight orations being pronounced over his grave.

* We are indebred to the notice in the Lancet, July 24, by Prof. Ball, for the factu stated in this obituary.-[EDB.] 